\title{
CONSTRUÇÃO DE UM SECADOR ROTATÓRIO E APLICABILIDADE NA SECAGEM DO AÇÚCAR
}

\section{ARTIGO ORIGINAL}

CARVALHO, Ludimila da Silva ${ }^{1}$

RIBEIRO, Kiany Richelli Silva ${ }^{2}$

EVANGELISTA, Edivania Rocha da Silva ${ }^{3}$

ANCKEN, Jeisiel Von ${ }^{4}$

GUIRALDELLI, Braz Lucas Olhier ${ }^{5}$

ALVES, Wenderli ${ }^{6}$

SANTOS, Alexsander Saves dos ${ }^{7}$

CARVALHO, Ludimila da Silva. Et al. Construção de um Secador Rotatório e aplicabilidade na secagem do açúcar. Revista Científica Multidisciplinar Núcleo do Conhecimento. Ano 04, Ed. 09, Vol. 05, pp. 85-100. Setembro de 2019. ISSN: 2448-

\footnotetext{
${ }^{1}$ Acadêmica em Engenharia Química.

${ }^{2}$ Acadêmica em Engenharia Química.

${ }^{3}$ Acadêmica em Engenharia Química.

${ }^{4}$ Bacharel em Química pela Universidade Brasil (2012) / Acadêmico de Engenharia Química.

${ }^{5}$ Acadêmico em Engenharia Química.

${ }^{6}$ Bacharel em Química pela Universidade Brasil (2012) / Acadêmico de Engenharia Química.

${ }^{7}$ Mestrado em Ciências Ambientais; Especialização em Fundamentando a Prática de Ensino do Professor; Aperfeiçoamento em Magistério; Graduação em Pedagogia; Graduação em Física.
} 
0959, Link de acesso: https://www.nucleodoconhecimento.com.br/engenhariaquimica/secador-rotatorio

\section{RESUMO}

Ao longo do tempo, em virtude da demanda crescente e rápida de produtos alimentícios, se fez necessário a criação de técnicas de produção. Uma delas, é o método de secagem de alimentos feito por sistemas mecânicos. Dessa forma, o presente trabalho teve por objetivo a confeccionar um secador rotatório em pequena escala. Detrás, foram realizados testes com amostras de açúcar úmido comprovando a operacionalidade por meio de análises laboratoriais.

Palavras Chaves: Operações unitárias, secagem, secador rotatório.

\section{INTRODUÇÃO}

Ao longo do tempo, em virtude da demanda crescente e rápida de produtos alimentícios, se fez necessário a criação de técnicas de produção. Uma delas, é o método de secagem de alimentos feito por sistemas mecânicos.

A secagem faz parte de inúmeras operações unitárias realizadas pela indústria, dado que, respectivamente, essa operação se tornou a mais usual.

De acordo com McCabe; Smith; Harriott (1993), as operações unitárias são etapas que compõem um processo, cada etapa é chamada de operação e podem ser aplicados tanto a processos físicos quanto químicos. Tais operações, são estudadas pela engenharia e são baseadas na ciência e na experiência. Em conformidade com os mesmos autores, uma série de princípios e técnicas são necessários para o tratamento das operações unitárias.

"Entre muitas outras finalidades, as operações unitárias visam reduzir o tamanho de sólidos a processar, separar componentes de misturas ou aquecer e resfriar sólidos e fluidos. São exemplos a filtração, a secagem" [...] (GOMIDE, 1983, p.3). 
Segundo Foust et al., (1982), secagem é a passagem de um líquido presente num sólido molhado para uma fase gasosa insaturada. De acordo com os mesmos autores, os sólidos secos são produtos valiosíssimos na indústria.

Geralmente a secagem é a última operação de uma série de outros processos, e o produto originário do secador está pronto para o empacotamento (MCCABE; SMITH; HARRIOTT, 1993).

A operação de secagem oferece inúmeras vantagens, tais como, o aumento da vida útil do produto, facilidade de transporte e comercialização, pois o alimento seco é leve, redução de perdas após a colheita, além de ser desnecessária a mão de obra especializada (CELESTINO, 2010).

A evaporação difere-se da secagem, enquanto na primeira a água é retirada como vapor em seu ponto de ebulição, na secagem a água é removida como vapor de ar (GEANKOPOLIS, 1993).

Conforme reportado por Gava (1998), só é possível o desenvolvimento de microrganismos em ambientes favoráveis como, taxa de umidade adequada, temperatura, dentre outros. Assim, o processo de secagem se caracteriza como um método de conservação de alimentos, pois reduz tanto a umidade que os microrganismos não conseguem se multiplicar.

Em seus estudos, Mujumdar (2006) conclui que dois fenômenos ocorrem quando um sólido úmido é exposto ao processo de secagem, a transferência de energia, principalmente na forma de calor e a transferência de umidade interna para a parte superficial do sólido.

Os materiais como os sólidos orgânicos retém umidade no interior das fibras ou em poros internos. De modo que o movimento da umidade nesta situação ocorre pela difusão do líquido por meio da estrutura do sólido (FOUST et al., 1982). 
O teor de umidade varia de acordo com o tipo de produto, por exemplo, o sal dinamarquês, geralmente, contém $0,5 \%$ de água, o carvão $4 \%$ e a maioria dos produtos alimentícios contém até 5\% (GEANKOPOLIS, 1993).

Existem dois métodos básicos de secagem, a secagem natural e a secagem artificial.

A secagem natural é a simples exposição do alimento ao sol. Adequados a regiões com temperatura média de $35^{\circ} \mathrm{C}$ a $40^{\circ} \mathrm{C}$ e baixos índices de poluição (CELESTINO, 2010).

Ainda de acordo com Celestino (2010), a secagem artificial é definida pelo uso de equipamentos na qual o alimento se encontra, e o processo de desidratação ocorre por um determinado período.

Mujumdar (2006) relata a existência de mais de 400 tipos de secadores artificiais, porém pouco mais 100 são de comum utilização.

Coulson e Richardson (2005) desenvolveram um estudo onde classificam os secadores por meio de algumas variáveis, tais como, o estado físico do alimento (líquido, pasta, sólido úmido), método do transporte do sólido, sistema de aquecimento (condução, convecção, radiação). Em um breve resumo, a maioria dos secadores estacionários como o secador a bandeja realiza a atividade de secagem por meio da condução, ademais, os secadores rotatórios de aquecimento direto realizam o processo por convecção, e por outro lado, os secadores rotativos de aquecimento indireto executa o processo por meio da condução.

Um dos secadores mais utilizados é o secador a bandejas (MUJUMDAR, 2006).

De acordo com Foust et al., (1982), o secador a bandejas é um equipamento de operação descontínua, formado por uma câmara, onde o material a ser seco é colocado sobre bandejas ou tabuleiros.

Outro tipo de secador, é o secador rotatório, constituído por um tubo cilíndrico ligeiramente inclinado em direção a saída, e o material a ser seco, geralmente sólidos 
granulares para este tipo de secador, move-se através do tubo quando gira (GEANKOPOLIS, 1993).

No interior dos secadores rotatórios são fixadas peças suspensoras ao longo do tubo com o objetivo de promover o cascateamento dos sólidos até a vazão de saída. Nestes secadores, o meio de aquecimento fornecido advém de gases de combustão, ou vapor superaquecido ou ar aquecido por eletricidade (FOUST et al., 1982).

Ainda de acordo com Foust et al., (1982), o tempo de retenção dos sólidos nos secadores rotatórios é de extremo interesse. Pois, é necessário um determinado tempo para que o gás ou ar secante perpasse todo o material completando o processo de secagem.

Dependendo da aplicação, o secador rotatório pode ser confeccionado em aquecimento direto e indireto e fluxo paralelo ou contracorrente.

No aquecimento direto, o gás quente ou ar passa diretamente sobre o alimento. No aquecimento indireto a fonte de calor é isolada do material a ser seco por tubos de metais ou paredes (MUJUMDAR, 2006).

Nos secadores de fluxo contracorrente, a alimentação é fixada em sentido oposto a corrente de ar, em contrapartida, nos secadores de fluxo paralelo, a corrente de ar e a alimentação deslocam-se na mesma direção.

\section{OBJETIVOS}

Projetar um secador rotatório em pequena escala.

Acompanhar o sistema de secagem utilizando amostras de açúcar úmido e analisar os dados obtidos.

\section{MATERIAIS E MÉTODOS}

No desenvolvimento do secador rotatório foram usados os seguintes materiais relacionados na Tabela 1. 
Tabela 1: Materiais utilizados e custos.

\begin{tabular}{|c|c|c|c|c|}
\hline MATERIAIS & UNIDADE & QUANTIDADE & $\begin{array}{l}\text { VALOR } \\
\text { UNITÁRIO }\end{array}$ & $\begin{array}{l}\text { VALOR } \\
\text { TOTAL }\end{array}$ \\
\hline ARRUELA $1 / 4$ & PÇ & 11 & $\mathrm{R} \$ 0,10$ & $\mathrm{R} \$ 1,10$ \\
\hline $\begin{array}{l}\text { BARRA CHATA DE INOX } \\
1 / 4\end{array}$ & M & 1,5 & $\mathrm{R} \$ 6,66$ & $\mathrm{R} \$ 9,99$ \\
\hline CAP DE PVC 6" & PÇ & 2 & $R \$ 15,00$ & $R \$ 30,00$ \\
\hline $\begin{array}{l}\text { CHAPA DE AÇO INOX T } \\
3 / 16\end{array}$ & $\mathrm{M}^{2}$ & 0,40 & $\mathrm{R} \$ 5,00$ & $\mathrm{R} \$ 2,00$ \\
\hline $\begin{array}{l}\text { CHAPA EXPANDIDA DE } \\
\text { AÇO INOX } 3 / 16\end{array}$ & PÇ & 0,30 & $\mathrm{R} \$ 40,00$ & $\mathrm{R} \$ 12,00$ \\
\hline CHAVE LIGA E DESLIGA & $\mathrm{PÇ}$ & 3 & $\mathrm{R} \$ 15,00$ & $\mathrm{R} \$ 45,00$ \\
\hline COOLER 110v & PÇ & 1 & $\mathrm{R} \$ 20,00$ & $\mathrm{R} \$ 20,00$ \\
\hline COROA DE 20 DENTES & PÇ & 3 & $\mathrm{R} \$ 15,00$ & $\mathrm{R} \$ 45,00$ \\
\hline COROA DE 46 DENTES & $\mathrm{PÇ}$ & 1 & $\mathrm{R} \$ 12,00$ & $\mathrm{R} \$ 12,00$ \\
\hline $\begin{array}{l}\text { CORRENTE DE MOTO } 80 \\
\text { CM }\end{array}$ & PÇ & 2 & $\mathrm{R} \$ 10,00$ & $\mathrm{R} \$ 20,00$ \\
\hline $\begin{array}{l}\text { DISCO DE CORTE } 2 \\
\text { TELAS } 41 / 2 ” \times 1 / 8 \times 7 / 8\end{array}$ & PÇ & 3 & $R \$ 16,00$ & $\mathrm{R} \$ 48,00$ \\
\hline $\begin{array}{l}\text { DISCO DE DESBASTE } 4 \\
1 / 2 " \times 1 / 4 \times 7 / 8\end{array}$ & PÇ & 2 & $\mathrm{R} \$ 22,00$ & $\mathrm{R} \$ 44,00$ \\
\hline ELETRODOS DE SOLDA & $\mathrm{Kg}$ & 0,50 & $\mathrm{R} \$ 25,00$ & $R \$ 12,50$ \\
\hline $\begin{array}{l}\text { ESCOVA ROTATIVA DE } \\
\text { CABELO } 1000 \mathrm{~W}\end{array}$ & PÇ & 1 & $\mathrm{R} \$ 170,00$ & $\mathrm{R} \$ 170,00$ \\
\hline FIO FLEXÍVEL & M & 10 & $\mathrm{R} \$ 0,82$ & $\mathrm{R} \$ 8,20$ \\
\hline $\begin{array}{l}\text { INVERSOR } \\
\text { FREQUÊNCIA }\end{array}$ & PÇ & 1 & $\mathrm{R} \$ 75,00$ & $\mathrm{R} \$ 75,00$ \\
\hline MDF & $\mathrm{M}^{2}$ & 1,50 & $\mathrm{R} \$ 25,00$ & $R \$ 37,50$ \\
\hline
\end{tabular}




\begin{tabular}{|c|c|c|c|c|}
\hline $\begin{array}{l}\text { MOTOR DE MÁQUINA } \\
\text { DE LAVAR USADO } 0,5 \\
\text { CV }\end{array}$ & $\mathrm{PÇ}$ & 1 & $\mathrm{R} \$ 29,00$ & $\mathrm{R} \$ 29,00$ \\
\hline PARAFUSO 1/4 POR 2"' & $\mathrm{PÇ}$ & 11 & $\mathrm{R} \$ 0,35$ & $\mathrm{R} \$ 3,85$ \\
\hline $\begin{array}{l}\text { PARAFUSO SOBERBO } 5 \\
\times 50 \mathrm{~mm}\end{array}$ & $\mathrm{PÇ}$ & 60 & $\mathrm{R} \$ 0,35$ & $\mathrm{R} \$ 21,00$ \\
\hline PORCA $1 / 4$ & $\mathrm{PÇ}$ & 11 & $\mathrm{R} \$ 0,15$ & $\mathrm{R} \$ 1,65$ \\
\hline $\begin{array}{l}\text { REDUTOR } \\
\text { VELOCIDADE } 1 \times 60\end{array}$ & $\mathrm{PÇ}$ & 1 & $\mathrm{R} \$ 200,00$ & $\mathrm{R} \$ 200,00$ \\
\hline ROLAMENTO & PÇ & 4 & $\mathrm{R} \$ 10,00$ & $\mathrm{R} \$ 40,00$ \\
\hline $\begin{array}{l}\text { SERVIÇOS DE TORNO E } \\
\text { SOLDA }\end{array}$ & $\mathrm{PÇ}$ & 1 & $\mathrm{R} \$ 60,00$ & $\mathrm{R} \$ 60,00$ \\
\hline TERMÔMETRO DIGITAL & PÇ & 1 & $\mathrm{R} \$ 10,00$ & $\mathrm{R} \$ 10,00$ \\
\hline TINTA LATEX & L & 1,0 & $\mathrm{R} \$ 12,00$ & $\mathrm{R} \$ 12,00$ \\
\hline TINTA SPRAY & $P C ̧$ & 3 & $\mathrm{R} \$ 20,00$ & $\mathrm{R} \$ 60,00$ \\
\hline $\begin{array}{l}\text { TUBO DE AÇO INOX } 1 \\
1 / 4 "\end{array}$ & M & 0,10 & $\mathrm{R} \$ 15,00$ & $\mathrm{R} \$ 1,50$ \\
\hline $\begin{array}{l}\text { TUBO DE AÇO INOX } 1 \\
1 / 2 "\end{array}$ & M & 0,40 & $\mathrm{R} \$ 20,00$ & $\mathrm{R} \$ 8,00$ \\
\hline TUBO DE AÇO INOX 5"' & M & 0,50 & $\mathrm{R} \$ 35,00$ & $\mathrm{R} \$ 17,50$ \\
\hline TUBO DE AÇO INOX 6"' & M & 0,20 & $\mathrm{R} \$ 40,00$ & $\mathrm{R} \$ 8,00$ \\
\hline TUBO DE PVC 6"' & $M$ & 0,25 & $\mathrm{R} \$ 15,00$ & $\mathrm{R} \$ 3,75$ \\
\hline TOTAL & & & & $\begin{array}{l}R \$ \\
1068,54\end{array}$ \\
\hline
\end{tabular}

Fonte: Os autores.

O equipamento utilizado neste trabalho foi fundamentado a partir de um secador rotatório de aquecimento direto e de fluxo contracorrente localizado na usina Coruripe no município de Carneirinho-MG. 
Para a confecção do secador, cortou-se $500 \mathrm{~mm}$ do tubo de inox de 5", 2 peças de $100 \mathrm{~mm}$ do tubo de inox de 6", $300 \mathrm{~mm}$ do tubo de inox de $11 / 4$ ", $100 \mathrm{~mm}$ do tubo de inox 1 1/2", 250mm do tubo de PVC de 6", 3 barras chatas de 1/4" de $500 \mathrm{~mm}$ de comprimento, 2 chapas 3/16" em forma de círculo de 6" de diâmetro, 2 chapas T 3/16 de $200 \mathrm{~mm}$, chapa MDF de $20 \mathrm{~mm}$ de espessura com $930 \times 780 \mathrm{~mm}$, 2 chapas MDF de $20 \mathrm{~mm}$ de espessura com $930 \times 110 \mathrm{~mm}$ e 2 chapas MDF de $20 \mathrm{~mm}$ de espessura com $780 \times 110 \mathrm{~mm}$.

Para a construção do tambor utilizou-se o tubo de inox de 5". Em seguida, soldou-se internamente no tambor 3 barras chatas de $1 / 4$ formando as palhetas internas do secador, conforme a imagem 1.

Imagem 1: Palhetas no interior do tambor.

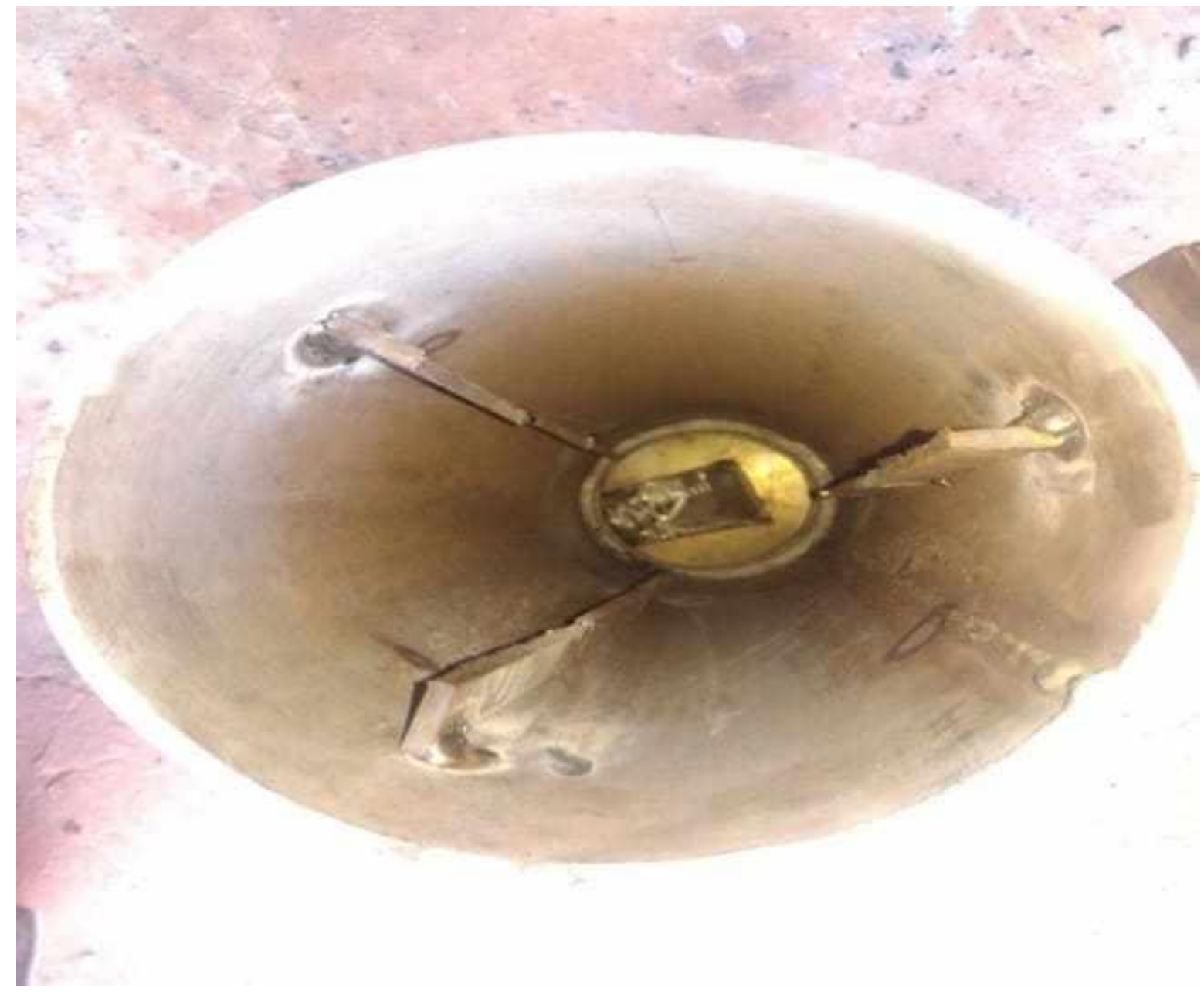

Fonte: Os autores. 
Junto ao tambor, foi acoplado o tubo de 6" nos extremos de cada lado. Após, realizouse um corte redondo no tubo de inox de 1 11/2" formando a vazão de entrada do produto no topo e a vazão de saída do ar quente na lateral, conforme a imagem 2. Soldou-se a peça em uma das extremidades.

Imagem 2: Vazão de entrada do produto no topo da peça e vazão de saída do ar quente, na lateral esquerda.

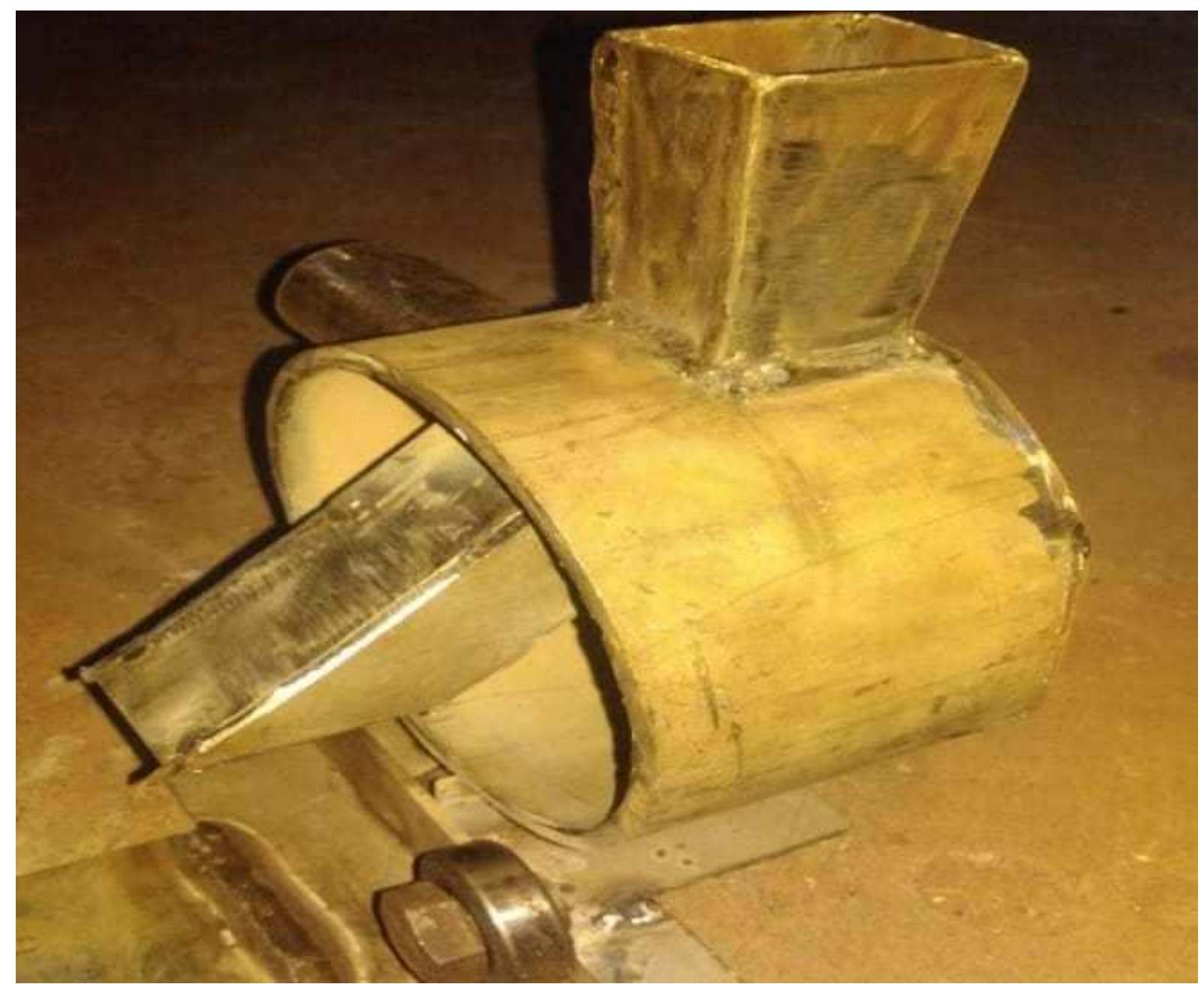

Fonte: Os autores.

Da mesma forma, externamente, foi soldado uma coroa de 46 dentes no tambor, conforme a imagem 3 , e 2 trilhos de apoio aos rolamentos na base confeccionado no torno, conforme a imagem 4. 
Imagem 3: Coroa de 46 dentes soldada ao tambor.

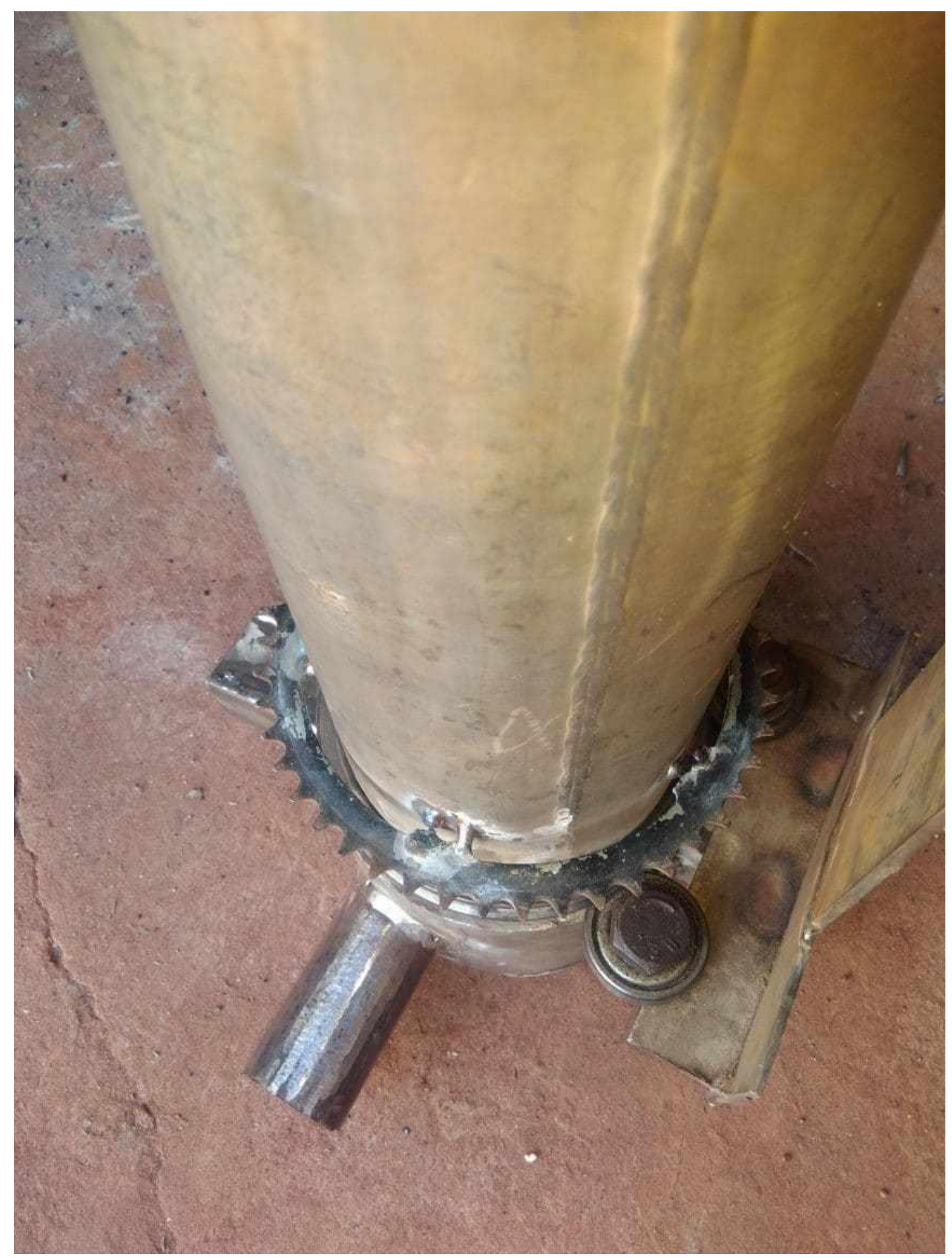

Fonte: Os autores. 
Imagem 4: Trilhos de apoio aos rolamentos

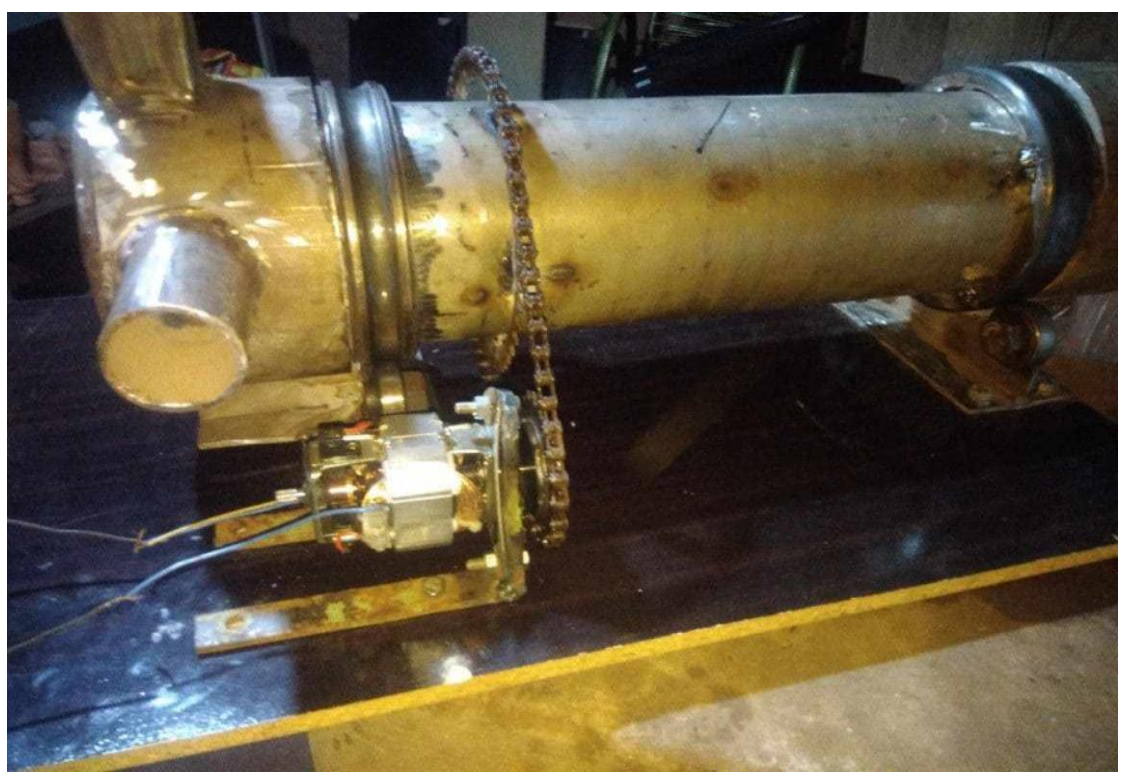

Fonte: Os autores.

$\mathrm{Na}$ extremidade oposta a vazão de entrada do produto, soldou-se o tubo de inox de 1 $1 / 4$ " de $100 \mathrm{~mm}$ formando a entrada do ar quente, conforme a imagem 5.

No mesmo ponto, logo abaixo do tubo, encontra-se a vazão de saída do produto.

Imagem 5: Tubo de entrada do ar quente e vazão de saída do produto.

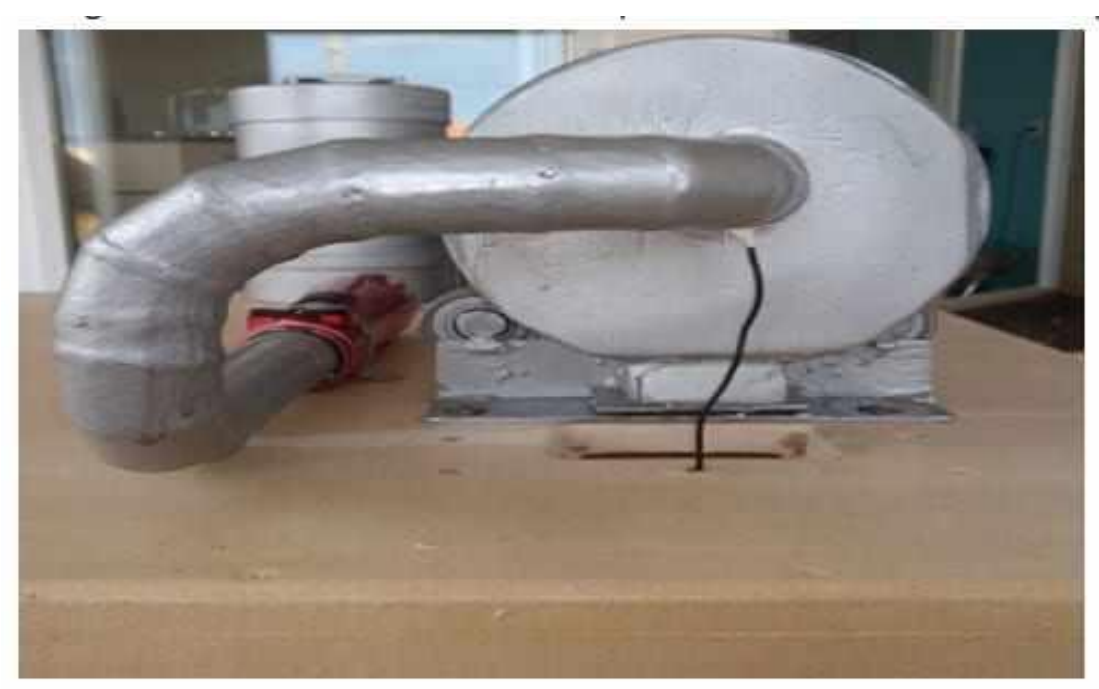

Fonte: Os autores. 
$\mathrm{Na}$ base do secador foram utilizadas duas chapas $\mathrm{T} 3 / 16$ de $20 \mathrm{~cm}$, onde foram instalados 4 rolamentos, 2 na entrada e 2 na saída, entre uma distância de $41 \mathrm{~cm}$.

Para a fonte de calor, utilizou-se a resistência de uma escova rotativa de cabelo de $1000 \mathrm{~W}$ que, posteriormente, foi instalada ao tubo de entrada do ar quente, conforme imagem 6.

Imagem 6: Escova rotativa instalada.

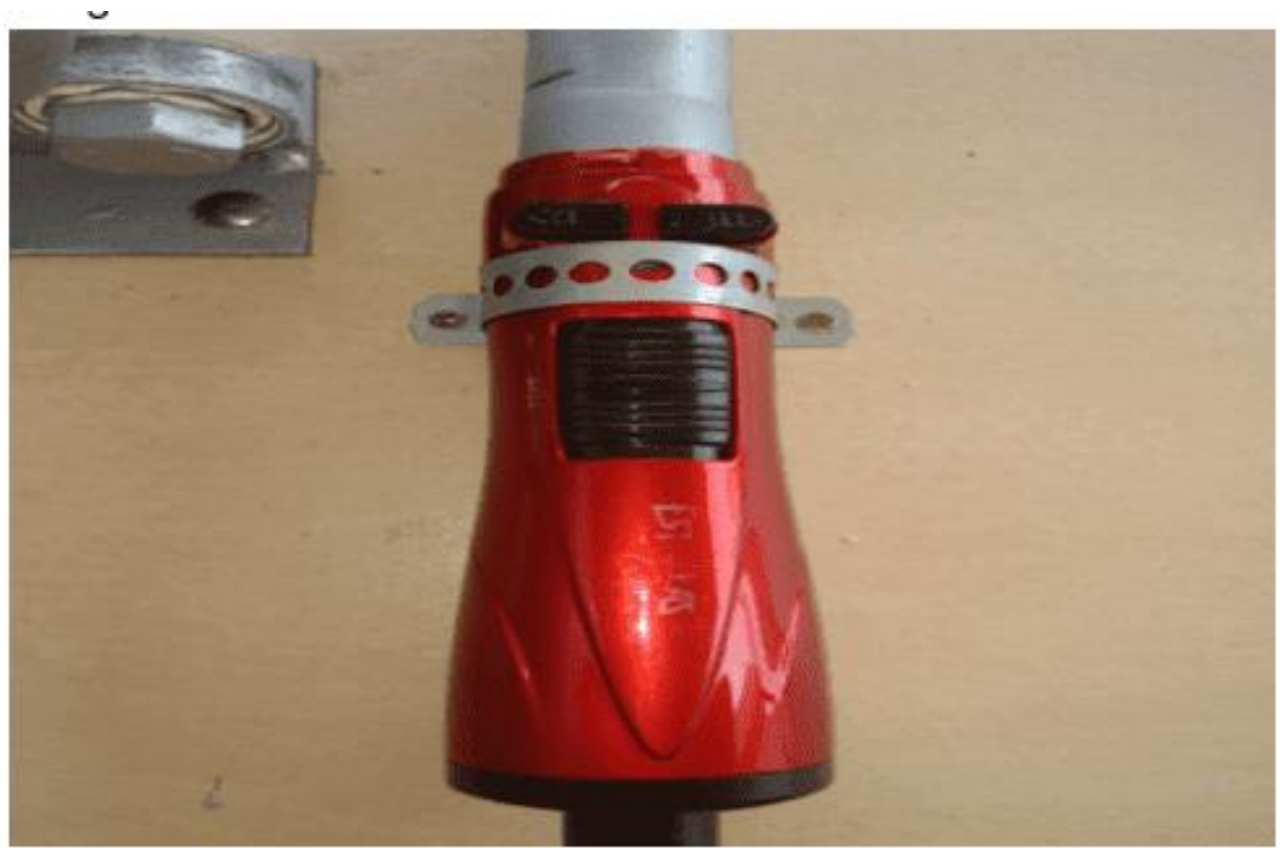

Fonte: Os autores.

Em seguida, foi confeccionado um exaustor com o tubo de PVC de 6" de $250 \mathrm{~mm}$ de comprimento, utilizando 2 cap. para capear as duas bocas do tubo e inserido um cooler sobre o exaustor, este por sua vez, instalado ao tubo de saída do ar quente, conforme a imagem 7 . 
Imagem 7: Exaustor instalado ao sistema.

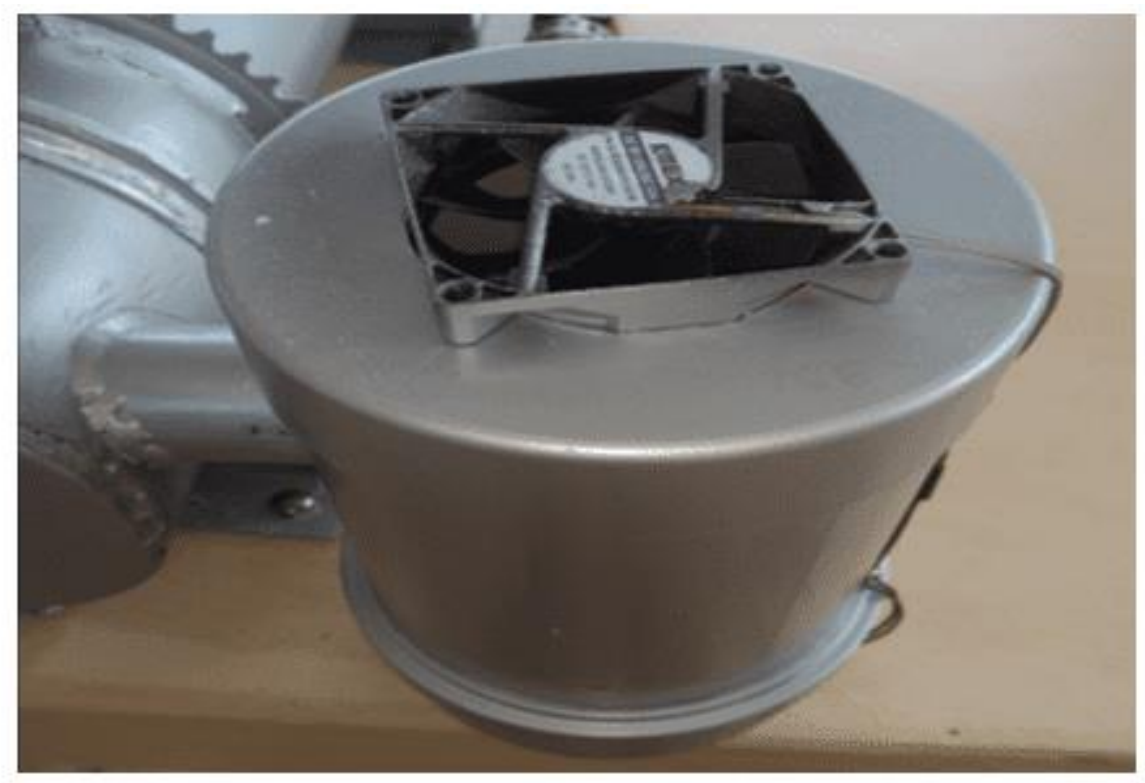

Fonte: Os autores.

Foi construída uma base de MDF de $930 \times 780 \times 110 \mathrm{~mm}$, onde foram feitos furos para parafusar o secador, motor, chave de liga desliga e termômetro.

O motor e o redutor foram instalados na lateral do secador, conforme a imagem 8.

Imagem 8: Motor (direito) e redutor (esquerdo) instalados.

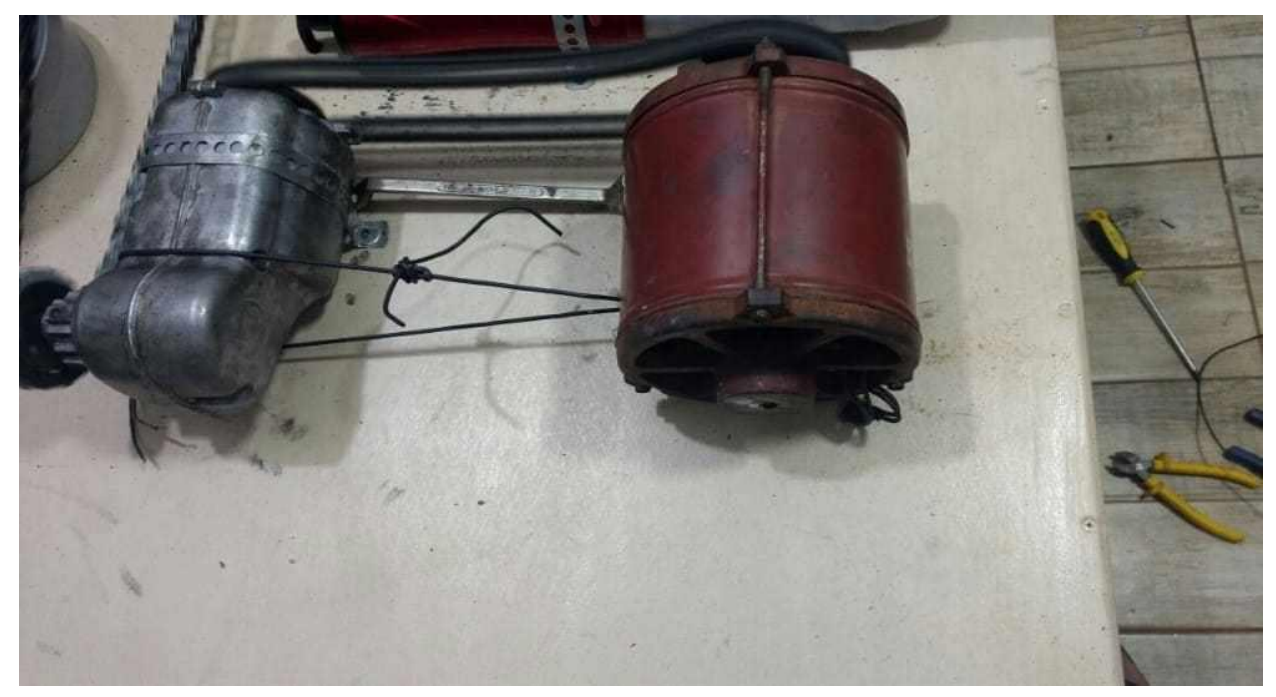

Fonte: Os autores.

RC: 37489

Disponível em: https://www.nucleodoconhecimento.com.br/engenharia-quimica/secador-rotatorio 
Nessa sequência, na polia do motor, foi utilizada uma coroa de 20 dentes balanceada no torno, fixado ao eixo do motor, em seguida, colocou-se a corrente de $80 \mathrm{~cm}$.

Por fim, o motor e o redutor foram cobertos com suporte MDF e toda a estrutura do secador foi devidamente pintada.

Imagem 9: Secador rotatório finalizado.

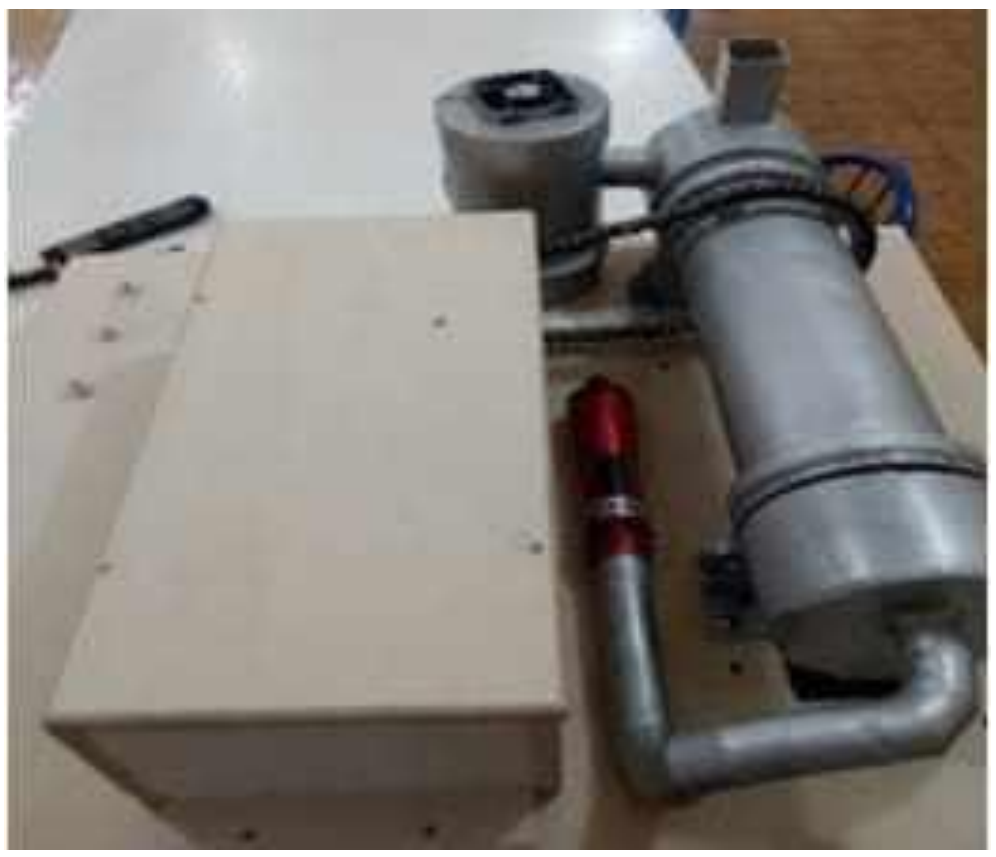

Fonte: Os autores.

\section{RESULTADOS EXPERIMENTAIS}

O primeiro e o segundo teste foram realizados com o objetivo de definir qual motor teria melhor desempenho quanto a rotação do tambor. Inicialmente, o motor escolhido foi o motor de ventilador de 200w, que após instalá-lo e ligá-lo, percebeu-se que a potência era insuficiente para movimentar o tambor.

No segundo teste, ainda com o secador vazio, o motor escolhido foi o motor de máquina de lavar roupas de $0,5 \mathrm{cv}$. Logo, notou-se que o motor atingiu o resultado esperado que era de movimentar o tambor, porém a velocidade com que o tambor girava estava muito alta e isso dificultaria o processo de secagem. 
No terceiro teste, introduziu-se junto ao sistema um redutor de velocidade ligado ao motor para diminuir as rotações do tambor, entretanto, para melhor ajuste também foi inserido um inversor de frequência resultando em uma rotação de 30 rpm.

Concluído os elementos mecânicos do engenho, realizou-se os testes com amostras de açúcar úmido, mais precisamente, o açúcar bruto, adquirido por meio de doação.

Neste projeto, os sólidos são inseridos manualmente.

No primeiro teste, utilizou-se $1 \mathrm{~kg}$ de açúcar a uma temperatura de $81^{\circ} \mathrm{C}$. Após 1 minuto, retirou-se $10 \mathrm{~g}$ do produto para a análise de umidade. Inicialmente o açúcar continha $1,07 \%$ de umidade e logo após o processo a umidade caiu para $0,15 \%$.

No segundo teste, utilizou-se uma quantidade maior de açúcar, mais precisamente, $4,5 \mathrm{~kg}$ sob uma temperatura de $88^{\circ} \mathrm{C}$ por 30 segundos. Realizou-se a análise de umidade com $10 \mathrm{~g}$ do produto e soube-se que no início o teor de umidade era $0,32 \%$ e depois da secagem diminuiu para $0,15 \%$, assim, pode-se calcular a velocidade de secagem nesse processo.

De antemão, calculou-se a área do tambor:

$A=2 \pi \cdot r \cdot(r+h)$

$A=2 \pi \cdot 0,0635 \cdot(0,0635+0,5)$

$A=0,224826507 \mathrm{~m}^{2}$

Logo, a velocidade de secagem é:

$R=W_{s} \cdot d x / A \cdot d \Theta$

$R=(0,010) \cdot\left(3,2 \times 10^{-3}-0,0015\right) / 0,224826507.30$

$\mathrm{R}=2,52 \times 10^{-6} \mathrm{~m} / \mathrm{s}$ 


\section{CONCLUSÃO}

O secador rotatório construído apresentou um bom desempenho do ponto de vista da secagem do açúcar, preservando as propriedades físicas e nutritivas do alimento.

Analisando os vários testes, notou-se que os conhecimentos limitados relacionados a mecânica dificultaram a elaboração do secador, visto que, precisou-se de aparelhos complementares como o redutor de velocidade e o inversor de frequência para ajustar as rotações do tambor, sendo que na indústria estes aparelhos auxiliadores não são necessários para a funcionalidade do secador em questão.

A respeito da velocidade de secagem, o secador como tal se mostrou eficiente, secando o açúcar quase que instantaneamente, considerando os resultados obtidos nos cálculos.

Nota-se que o objetivo proposto foi alcançado, tendo em vista, que o açúcar bruto deve conter entre $0,10 \%$ e $0,15 \%$ de umidade, e através das análises realizadas em laboratório pode-se constatar os respectivos teores.

\section{REFERÊNCIAS}

CELESTINO, SONIA MARIA COSTA. Princípios de secagem de alimentos, 1.ed. (edição online). Planaltina, DF: Embrapa Cerrados, 2010. Disponível em: https://ainfo.cnptia.embrapa.br/digital/bitstream/item/77765/1/doc-276.pdf. Acesso em: 07/01/2019.

FOUST, A; S.; WENZEL, L. A.; CLUMP, C. W.; MAUS, L.; ANDERSEN, L. B. Princípios das operações unitárias. Tradução por Horácio Macedo. 2.ed. Rio de Janeiro: LTC, 1982.

GAVA, ALTANIR. J. Princípios de tecnologia de alimentos, 1.ed. São Paulo: Nobel, 1998. 
GEANKOPOLIS, CHRISTIE. J. Transport processes and unit operations, 3.ed. New Jersey: Prentice-hall, 1993.

GOMIDE, REYNALDO. Operações unitárias, operações com sistemas sólidos granulares, 1.ed. São Paulo: Edição do autor, 1983, p.3.

Informe técnico - Parâmetros de qualidade do açúcar e amarelecimento no armazenamento. Mídia Digital. Disponível em: www.ceagesp.gov.br/wpcontent/uploads/2015/01/palestra.danilo.tostes.pdf. Acesso em: 10/07/2019.

MCCABE, W. L.; SMITH, J. C.; HARRIOTT, P. Unit operations of chemical engineering, 5.ed. Singapore: Mc Graw Hill, Inc. 1993.

MUJUMDAR, A. S. Manual de secagem industrial, 1.ed. Singapore: Taylor \& Francis Group, LLC. 2006.

SINNOTT, R. K. Chemical engineering design, Coulson \& Richardson's chemical engineering series, 4.ed. Reino Unido: Elsevier Butterworth Heinemann, 2005, vol.6.

Enviado: Agosto, 2019.

Aprovado: Setembro, 2019. 